\title{
Case Report \\ Two Different Cell Populations Is an Important Clue for Diagnosis of Primary Cutaneous Adenoid Cystic Carcinoma: Immunohistochemical Study
}

\author{
Banu Ince Alkan, ${ }^{1}$ Onder Bozdogan, ${ }^{2}$ Müjde Karadeniz, ${ }^{1}$ and Nazan Bozdoğan' \\ ${ }^{1}$ Pathology Department, Abdurrahman Yurtaslan Oncology Education and Research Hospital, Ankara, Turkey \\ ${ }^{2}$ Department of Pathology, Numune Education and Research Hospital, Ankara, Turkey \\ Correspondence should be addressed to Onder Bozdogan; uplpa04@hotmail.com
}

Received 25 September 2016; Accepted 8 December 2016; Published 24 January 2017

Academic Editor: Tibor Tot

Copyright ( 2017 Banu Ince Alkan et al. This is an open access article distributed under the Creative Commons Attribution License, which permits unrestricted use, distribution, and reproduction in any medium, provided the original work is properly cited.

Primary cutaneous adenoid cystic carcinoma (PCACC) is a very rare malignancy. The differential diagnosis of PCACCs in pathology practice can be difficult and a group of primary and metastatic lesions, including adenoid basal cell carcinoma of the skin, should be considered in the differential diagnosis. Besides histomorphological clues, immunohistochemistry studies are very helpful in the differential diagnosis of PCACC. We report herein a case of PCACC with extensive immunohistochemical studies and review the literature from an immunohistochemistry perspective.

\section{Introduction}

Primary cutaneous adenoid cystic carcinoma (PCACC) is a very rare malignancy of the skin [1]. The histopathology of PCACC is very similar to adenoid cystic carcinoma (ACC) at other sites [2]. PCACCs have a tendency to recur locally but rarely show metastasis to the lymph nodes or distant organs [3]. We report herein a case of PCACC with immunohistochemical (IHC) findings and review the literature from an IHC perspective.

\section{Case Report}

A 54-year-old male patient presented with a nodular lesion on his back. Physical examination showed a nodular, oval cutaneous lesion without specific features. The lesion was a grossly well-circumscribed, gray-tan, $2 \times 2 \times 1.5 \mathrm{~cm}$ intradermal nodule. Microscopic sections revealed tumor cells, which were arranged in nests, tubular patterns, cribriform patterns, and solid islands (Figures 1(a) and 1(b)). The cell nests consisted of two cell types: polygonal cells, which were localized at the center of the islands or around luminal and cystic spaces, and basaloid cells, which were located at the periphery of the islands. Solid islands were also formed from basaloid cells. The basophilic/eosinophilic granular secretions were readily detected in the lumina. The lesion had no connection with the epidermis and no lymphovascular space or perineural invasion. Mitoses were readily detected. To compare the histopathology and immunohistochemistry of the tumor, a case of classical adenoid-type basal cell carcinoma (A-BCC) in an 88-year-old female was also studied (Figures 1 (c) and $1(d))$.

An IHC study was performed for two patients using the Ventana Benchmark Ultra automated immunohistochemistry system (Ventana Medical Systems, Inc., Tucson, AZ, USA). CK7 (1/200, monoclonal; Thermo Fisher Scientific, Inc., Waltham, MA, USA), CEA (1/200, monoclonal; Thermo Fisher Scientific, Inc.), EMA (1/200, monoclonal; Cell Marque; Sigma-Aldrich, St. Louis, MO, USA), BerEP4 (1/50, monoclonal; Cell Marque), Laminin B2 (1/100, monoclonal; Thermo Fisher Scientific, Inc.), CD117 (1/200, polyclonal; Thermo Fisher Scientific, Inc.), and CD43 (1/100, monoclonal; Ventana) were applied to paraffin sections of both cases. Further IHC staining examinations were performed on paraffin sections of the PCACC case; these examinations included S100 (1/200, monoclonal; Cell Marque), collagen 4 


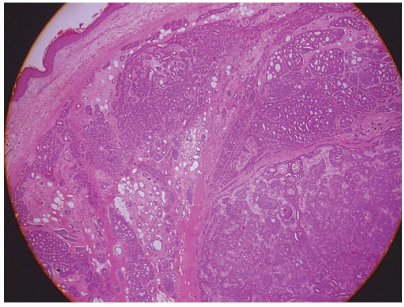

(a)

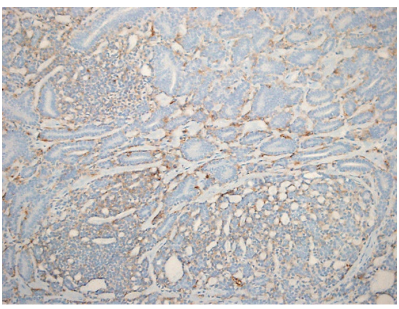

(e) $\mathrm{CD} 43$

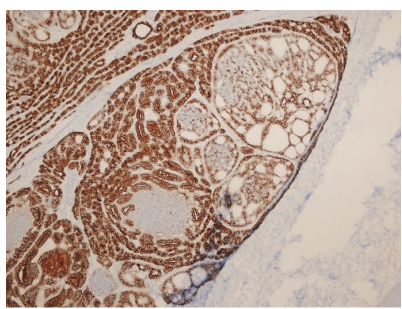

(i) $\mathrm{CK} 7$

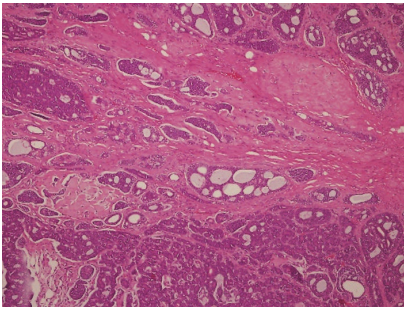

(b)

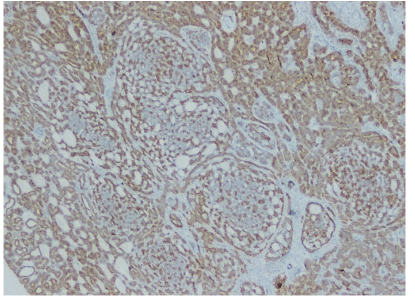

(f) $\mathrm{CD} 117$

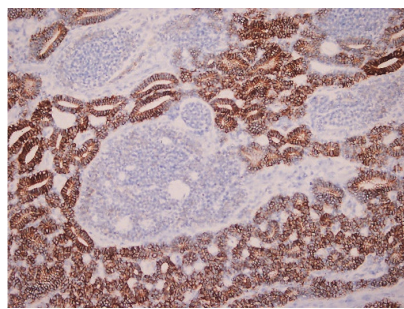

(j) BerEp4

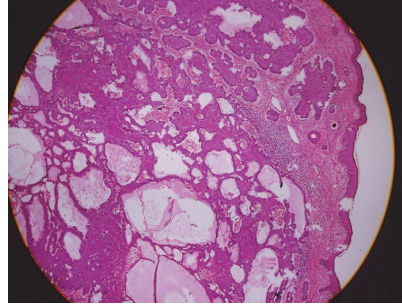

(c)

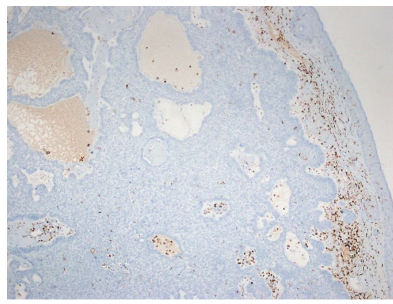

(g) CD43

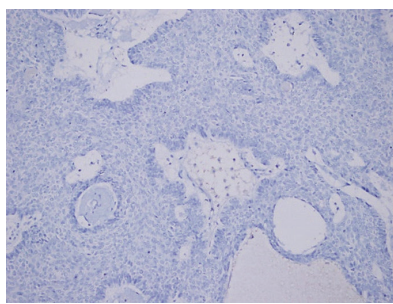

(k) $\mathrm{CK} 7$

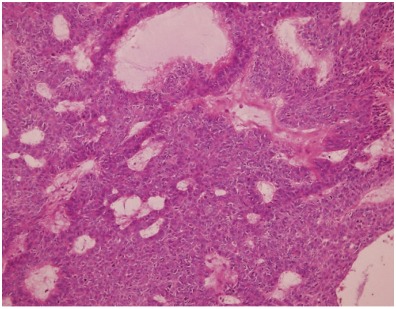

(d)

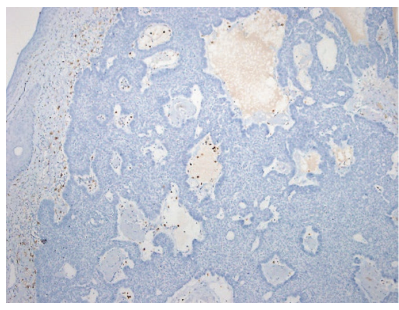

(h) CD117

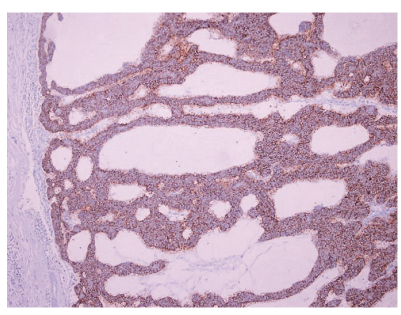

(l) BerEp4

Figure 1: Primer cutaneous adenoid cystic carcinoma (PCACC) (left two columns). Adenoid basal cell carcinoma (A-BCC) (right two columns). (a-b). Typical regular cribriform pattern is readily detected in PCACC. (c-d). However, pseudoluminal areas are not regular, and the well-defined cribriform patterns are not seen in A-BCC. CD117 (f) and CK7 (i) are positive in PCACCs but not in A-BCC (h, k). CD43 positivity is heterogenoeus in PCACC (e) but no positivity is detected except for inflammatory cells in A-BCC (g). BerEp4 positivity is seen in both lesions ( $\mathrm{j}, \mathrm{l})$. A-BCC shows diffuse positivity (l), but only ductal cell positivity in PCACC (j). Original magnifications: (a, c) $\times 40$; (b, e, f, g, h, i, k, l) $\times 100 ;(d, j) \times 200$.

(1/50, cocktail; Thermo Fisher Scientific, Inc.), p63 (1/100, monoclonal; Biocare Medical, Concord, CA 94520, USA), SMA (1/200, monoclonal; Thermo Fisher Scientific, Inc.), and CK5/6 (1/100, monoclonal; Thermo Fisher Scientific, Inc.).

In the lesion, the two different areas (luminal and basal) were differentiated according to the IHC results, which is similar to the histology. The polygonal (ductal/epithelial) cells were strongly stained by CD117, CK7, and BerEP4 (Figures 1(f), 1(i), and 1(j)). The basaloid (myoepithelial) cells showed positivity for SMA and p63 (Figure 2(a)). CEA and EMA positivity were also detected in the small number of luminal areas (Figure 2(b)). Laminin B2 and CD43 showed heterogeneous and medium intensity positivity (Figure 1(e)). CK5/6 was also strongly positive (Figure $2(\mathrm{c})$ ). Collagen 4 positivity highlighted the luminal material (Figure 2(d)). However, S100 positivity was not detected (Figure 2(e)). The A-BCC case showed no real glandular lumina on histopathological examination, and there was no clear-cut differentiation between the two cells. The A-BCC case showed diffuse BerEP4 positivity but was negative for EMA, CK7, CD117, CEA, Laminin B2, and CD43 (Figures 1(g), 1(h), 1(k), and 1(l)).
Clinically, to exclude the possibility of a metastatic lesion, the patient underwent further radiological examinations. However, no further lesion was detected. Therefore, the case was diagnosed as primary cutaneous adenoid cystic carcinoma (PCACC) grade 2 using the clinical, morphological, and IHC data [27].

\section{Discussion}

Although ADCCs of the salivary gland and the upper airways are commonly observed in routine clinical practice, PCACCs are very rare tumors, with $<100$ cases, including small series, having been reported previously $[1,26,28]$.

Histopathologically, PCACCs consist of basaloid cells, which are arranged as cribriform nests, tubules, cords, and solid areas in the dermis and subcutis $[1,29]$. The luminal areas usually consist of alternating eosinophilic or basophilic secretions [1]. The tumor cells show two distinct types of differentiation: ductal/epithelial differentiation around pseudocysts and myoepithelial differentiation in the outer layers of cell nodules $[2,16]$. 


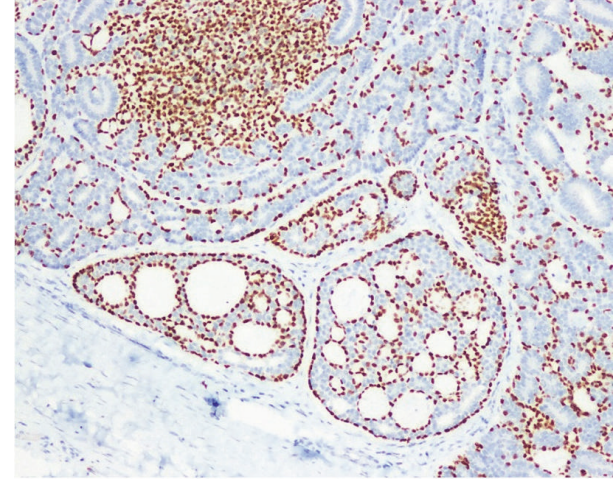

(a) p63

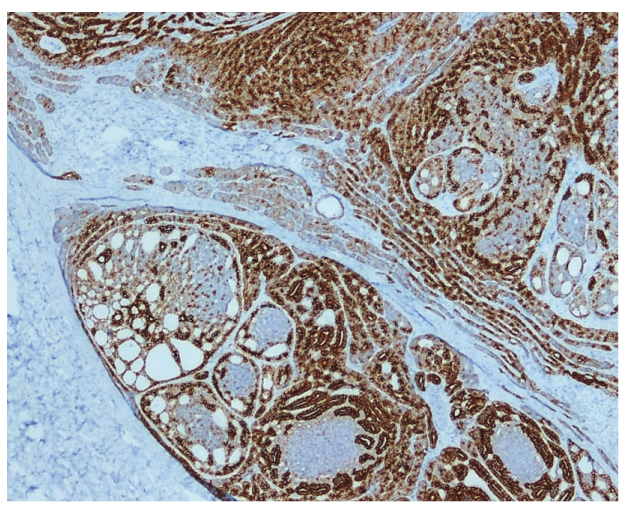

(c) $\mathrm{CK} 5 / 6$

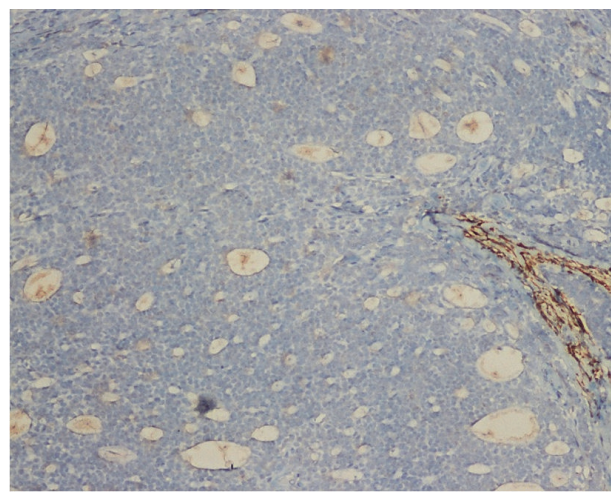

(e) $\mathrm{S} 100$

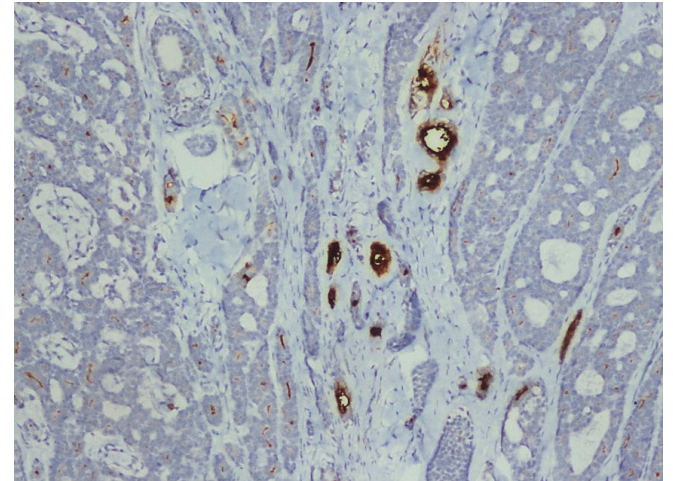

(b) EMA

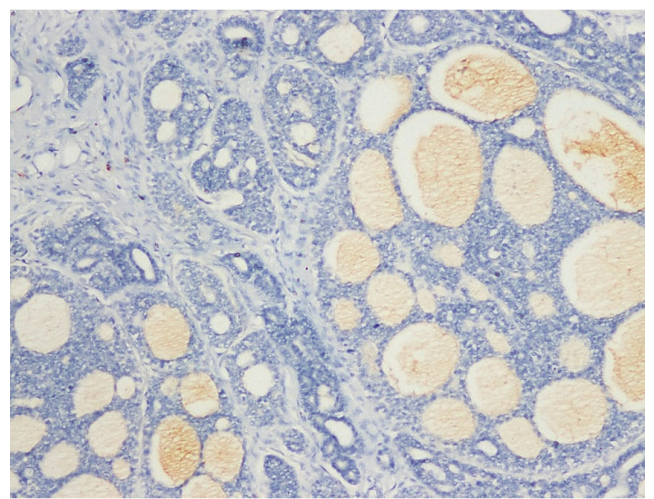

(d) Collagen

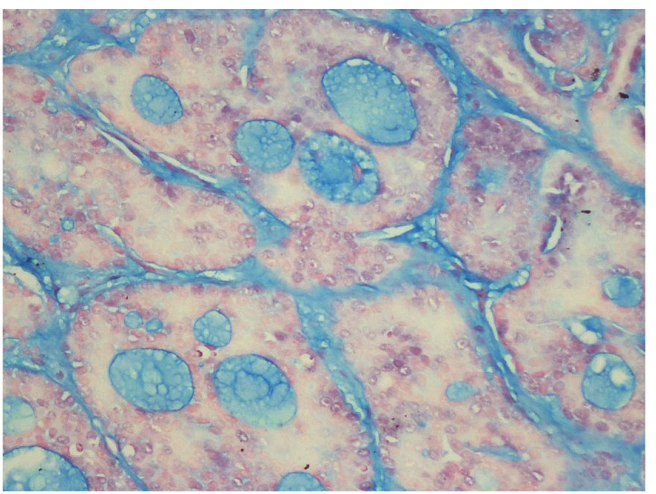

(f) Alcian Blue

FIGURE 2: Primary cutaneous adenoid cystic carcinoma. (a). p63 highlights the myoepithelial cells. (b). EMA shows positivity in only a few lumina. (c). CK5/6 positivity in PCACC. (d). Although collagen 4 positivity has weak or medium intensity, it highlights the luminal material. (e). S100 is negative in our case and only positive in dendritic cells. (f). Alcian Blue positivity in luminal secretion. Original magnification: $(\mathrm{a}, \mathrm{b}, \mathrm{c}, \mathrm{e}) \times 100$; (d) $\times 200$; (f) $\times 400$.

The differential diagnosis of PCACCs in pathology practice can be difficult. Adenoid basal cell carcinoma, primary mucinous carcinoma of the skin, metastatic breast carcinoma, eccrine adenoma, syringoma, mixed tumor of the skin, metastasis from primary ACCs of the salivary gland, and rare primary cutaneous cribriform carcinoma should be considered in the differential diagnosis $[1,25,30]$. The importance of immunohistochemistry has been well demonstrated in the differential diagnosis of PCACC [13]. Because the tumor cells show ductal and myoepithelial differentiation, IHC markers highlight different positivity in two different cell populations. In the present case study, PCACC showed BerEp4, CEA, CD117, and CK7 expression in the regions neighboring the luminal areas. p63 and SMA positivity were detected in myoepithelial cells at the periphery of the cell islands. The two different cell populations provide an important clue for diagnosis.

Due to the problems of differential diagnosis, groups of IHC markers were examined in the previous literature (Table 1), and the main differential diagnosis was between 
TABLE 1: Summary of immunohistochemical studies in the literature ${ }^{\&}$.

\begin{tabular}{|c|c|c|c|c|}
\hline IHC marker & Positivity & Percentage & Notes & References \\
\hline PAN-keratin & $10 / 10$ & $100 \%$ & Including AE1/AE3 keratin & {$[4-11]$} \\
\hline Alfa-lactalbumin & $1 / 1$ & $100 \%$ & & [9] \\
\hline Amylase & $1 / 1$ & $100 \%$ & & {$[9]$} \\
\hline Ber-ep $4^{*}$ & $1 / 2$ & $50 \%$ & & {$[12]$} \\
\hline Blood group isoantigens & $0 / 1$ & $0 \%$ & & [9] \\
\hline B2-microglobulin & $0 / 1$ & $0 \%$ & & [9] \\
\hline Calponin & $2 / 2$ & $100 \%$ & & {$[11]$} \\
\hline CAM5.2 & $0 / 1$ & $0 \%$ & & [5] \\
\hline CD10 & $1 / 2$ & $50 \%$ & & {$[5,12]$} \\
\hline CD $43^{*}$ & $2 / 3$ & $66,6 \%$ & & [13] \\
\hline CD56 & $1 / 1$ & $100 \%$ & & {$[5]$} \\
\hline CD57 (Leu7) & $0 / 1$ & $0 \%$ & & [8] \\
\hline $\mathrm{CD}_{117^{*}}$ & $37 / 37$ & $100 \%$ & & {$[1,5,6,12-16]$} \\
\hline CEA $^{*}$ & $24 / 33$ & $72,7 \%$ & Focal, luminal positivity & {$[1,5-8,11,12,17-22]$} \\
\hline $\mathrm{CK} 5 / 6^{*}$ & $17 / 17$ & $100 \%$ & & {$[5,14]$} \\
\hline $\mathrm{CK} 7^{*}$ & $20 / 20$ & $100 \%$ & & {$[5,10,12,14]$} \\
\hline CK10 & $0 / 1$ & $0 \%$ & & {$[10]$} \\
\hline CK15 & $13 / 14$ & $92,8 \%$ & & {$[14]$} \\
\hline CK18 & $1 / 1$ & $100 \%$ & & {$[10]$} \\
\hline CK19 & $1 / 2$ & $50 \%$ & & {$[5,12]$} \\
\hline CK20 & $0 / 1$ & $0 \%$ & & {$[5]$} \\
\hline D2-40 & $13 / 15$ & $86,6 \%$ & & {$[14]$} \\
\hline $\mathrm{EMA}^{*}$ & $27 / 30$ & $90 \%$ & Focal, luminal positivity & {$[1,4-6,8,9,11,12,17-19,22,23]$} \\
\hline GCDFP-15 & $0 / 1$ & $50 \%$ & & {$[12]$} \\
\hline HMWCK & $6 / 6$ & $100 \%$ & Including 34Be12 clone & {$[5,11,17,18,21]$} \\
\hline Laminin* & $3 / 3$ & $100 \%$ & & {$[17,24]$} \\
\hline LMWK & $4 / 4$ & $100 \%$ & & {$[8,17,18,21]$} \\
\hline MNF-116 & $14 / 14$ & $100 \%$ & & {$[1,22]$} \\
\hline P16 & $1 / 1$ & $100 \%$ & & {$[16]$} \\
\hline p63* & $17 / 19$ & $89,4 \%$ & & {$[5,12,14]$} \\
\hline Peanut agglutinin (PNA) & $1 / 1$ & $100 \%$ & & [9] \\
\hline S-100* & $28 / 30$ & $93,3 \%$ & Generally focal positivity & {$[1,5-9,11,12,17-23]$} \\
\hline SMA $^{*}$ & $33 / 36$ & $91,6 \%$ & Including one immunoflourescent study & {$[1,5,10,11,14,18,20]$} \\
\hline SOX-10 & $19 / 19$ & $100 \%$ & & {$[14]$} \\
\hline Type IV collagen* & $12 / 13$ & $92,3 \%$ & & {$[1,17,24]$} \\
\hline Vimentin & $13 / 16$ & $81,2 \%$ & & {$[8,10,14]$} \\
\hline
\end{tabular}

[4-12, 14, 15, 17-24].

${ }^{\&}$ Adenoid cystic carcinoma of the eye and eyelid excluded. * Including this case.

PCACC and A-BCC. Although peripheral palisading of tumor cells, continuity with the epidermis or adjacent hair follicle, and retraction artifacts between the tumor island and stroma are important features of A-BCC, distinction may not be easy in routine pathological investigations especially small biopsy specimens (Table 2) [31]. Therefore, immunohistochemistry may be helpful for differential diagnosis in the presence of these two similar entities [13]. Dessauvagie and Wood emphasized the importance of the CD117 and CD43 antibodies. CD117 positivity was present in all of the ACCs, and CD43 positivity was present in $40 \%$ of the ACCs. The BCCs showed no CD43 staining, and only $20 \%$ of the A-BCCs were positive for CD117 [13]. We also found CD117 and CD43 positivity in the PCACC but not in the A-BCC. However, a conflicting report was published by Terada, who showed that 93\% of BCCs were positive for CD117 [32]. Our experiences showed that CK7 positivity is rare in BCC and assists in the differentiation between sweat gland lesions and BCCs. The classical markers, CEA and EMA, are expected to be positive in the ductal cells of PCACC but generally not in classical ABCC $[1,31]$. Furthermore, the two different cell populations are not detected in A-BCCs.

The cribriform areas of spiradenomas should also be considered in the differential diagnosis. However, this change usually occurs focally, and the typical morphological features of spiradenomas are readily detected. Although the two cell 
TABLE 2: Differential diagnosis of primary cutaneous adenoid cystic carcinoma."

\begin{tabular}{|c|c|c|c|}
\hline Main differential diagnosis & Morphologic clues & Immunohistochemistry & Other \\
\hline Adenoid basal cell carcinoma & $\begin{array}{l}\text { (i) Peripheral palisading } \\
\text { (ii) Retraction artifact } \\
\text { (iii) Continuing with } \\
\text { epidermis or hair follicle } \\
\text { (iv) Lack of two cell } \\
\text { populations }\end{array}$ & $\begin{array}{c}\text { (i) CEA, EMA negative } \\
\text { (ii) CD117, CK7 usually } \\
\text { negative }\end{array}$ & $\begin{array}{l}\text { Although the staining } \\
\text { pattern is not the same, } \\
\text { Ber-Ep4 may not be very } \\
\text { helpful, with positivity in } \\
\text { both lesions. }\end{array}$ \\
\hline
\end{tabular}

(i) Epithelial attenuation

(ii) No perineural invasion

Primary cutaneous cribriform carcinoma (iii) Micropapilla formation

(i) Myoepithelial markers

(p63, calponin, and SMA)

(iv) Lack of two cell usually negative populations

\begin{tabular}{|c|c|c|c|}
\hline Metastatic ACC & (i) Similar morphology & $\begin{array}{l}\text { (i) Similar } \\
\text { immunohistochemical } \\
\text { findings }\end{array}$ & $\begin{array}{l}\text { Differential diagnosis } \\
\text { should be done on clinical } \\
\text { grounds. }\end{array}$ \\
\hline Cribriform patterns in spiradenomas & $\begin{array}{l}\text { (i) Focal cribriform areas } \\
\text { with typical spiradenoma } \\
\text { morphology } \\
\text { (ii) Two cell populations } \\
\text { may be found but may be } \\
\text { more irregular }\end{array}$ & N/A & $\begin{array}{c}\text { ACC-like areas show } \\
\text { myoepithelial } \\
\text { differentiation and may be } \\
\text { positive with p63 and SMA. }\end{array}$ \\
\hline Metastatic breast carcinoma & $\begin{array}{l}\text { (i) Lack of two cell } \\
\text { populations } \\
\text { (ii) Cancer cells in } \\
\text { lymphovascular spaces }\end{array}$ & $\begin{array}{c}\text { (i) Myoepithelial markers } \\
\text { (p63, calponin, and SMA) } \\
\text { usually negative }\end{array}$ & $\begin{array}{l}\text { Strong ER and PR may } \\
\text { point out metastatic breast } \\
\text { carcinoma, but adnexal } \\
\text { neoplasms may also be } \\
\text { positive. }\end{array}$ \\
\hline
\end{tabular}

${ }^{*}$ This table is established by using $[1-3,13,16,25-33]$. ACC: adenoid cystic carcinoma.
CD117 is not helpful, with positivity in both lesions. 
[9] M. R. Wick and P. E. Swanson, "Primary adenoid cystic carcinoma of the skin. A clinical, histological, and immunocytochemical comparison with adenoid cystic carcinoma of salivary glands and adenoid basal cell carcinoma," The American Journal of Dermatopathology, vol. 8, no. 1, pp. 2-13, 1986.

[10] T. H. van der Kwast, V. D. Vuzevski, F. Ramaekers, M. T. Bousema, and T. Van Joost, "Primary cutaneous adenoid cystic carcinoma: case report, immunohistochemistry, and review of the literature," British Journal of Dermatology, vol. 118, no. 4, pp. 567-577, 1988.

[11] E. Naylor, P. Sarkar, C. S. Perlis, D. Giri, D. R. Gnepp, and L. Robinson-Bostom, "Primary cutaneous adenoid cystic carcinoma," Journal of the American Academy of Dermatology, vol. 58, no. 4, pp. 636-641, 2008.

[12] D. Rocas, C. Asvesti, A. Tsega, P. Katafygiotis, and J. Kanitakis, "Primary adenoid cystic carcinoma of the skin metastatic to the lymph nodes: immunohistochemical study of a new case and literature review," The American Journal of Dermatopathology, vol. 36, no. 3, pp. 223-228, 2014.

[13] B. F. Dessauvagie and B. A. Wood, "CD117 and CD43 are useful adjuncts in the distinction of adenoid cystic carcinoma from adenoid basal cell carcinoma," Pathology, vol. 47, no. 2, pp. 130133, 2015.

[14] J. P. North, T. H. McCalmont, A. Fehr, A. van Zante, G. Stenman, and P. E. LeBoit, "Detection of MYB alterations and other immunohistochemical markers in primary cutaneous adenoid cystic carcinoma," The American Journal of Surgical Pathology, vol. 39, no. 10, pp. 1347-1356, 2015.

[15] J. Barnes and C. Garcia, "Primary cutaneous adenoid cystic carcinoma: a case report and review of the literature," Cutis, vol. 81, no. 3, pp. 243-246, 2008.

[16] A. O. Morrison, J. M. Gardner, S. M. Goldsmith, and D. C. Parker, "Primary cutaneous adenoid cystic carcinoma of the scalp with p16 expression: a case report and review of the literature," American Journal of Dermatopathology, vol. 36, no. 9, pp. e163e166, 2014.

[17] C. Cacchi, S. Persechino, L. Fidanza, and A. Bartolazzi, "A primary cutaneous adenoid-cystic carcinoma in a young woman. Differential diagnosis and clinical implications," Rare Tumors, vol. 3, no. 1, article e3, 2011.

[18] L. Doganay, S. Bilgi, C. Aygit, and S. Altaner, "Primary cutaneous adenoid cystic carcinoma with lung and lymph node metastases," Journal of the European Academy of Dermatology and Venereology, vol. 18, no. 3, pp. 383-385, 2004.

[19] M. Weekly, D. D. Lydiatt, W. M. Lydiatt, S. C. Baker, and S. L. Johansson, "Primary cutaneous adenoid cystic carcinoma metastatic to cervical lymph nodes," Head \& Neck, vol. 22, no. 1, pp. 84-86, 2000.

[20] C. Urso, A. Giannini, I. Rubino, and R. Bondi, "Adenoid cystic carcinoma of sweat glands: report of two cases," Tumori, vol. 77, no. 3, pp. 264-267, 1991.

[21] S. E. Chang, S. J. Ahn, J. H. Choi, K. J. Sung, K. C. Moon, and J. K. Koh, "Primary adenoid cystic carcinoma of skin with lung metastasis," Journal of the American Academy of Dermatology, vol. 40, no. 4, pp. 640-642, 1999.

[22] N. Kato, K. Yasukawa, and T. Onozuka, "Primary cutaneous adenoid cystic carcinoma with lymph node metastasis," The American Journal of Dermatopathology, vol. 20, no. 6, pp. 571$577,1998$.

[23] T. Torres, M. Caetano, R. Alves, M. Horta, and M. Selores, “Tender tumor of the scalp: clinicopathologic challenge. Primary cutaneous adenoid cystic carcinoma," International Journal of Dermatology, vol. 49, no. 6, pp. 605-607, 2010.

[24] K. Fukai, M. Ishii, H. Kobayashi et al., "Primary cutaneous adenoid cystic carcinoma: ultrastructural study and immunolocalization of types I, III, IV, V collagens and laminin," Journal of Cutaneous Pathology, vol. 17, no. 6, pp. 374-380, 1990.

[25] A. Rütten, H. Kutzner, T. Mentzel et al., "Primary cutaneous cribriform apocrine carcinoma: a clinicopathologic and immunohistochemical study of 26 cases of an under-recognized cutaneous adnexal neoplasm," Journal of the American Academy of Dermatology, vol. 61, no. 4, pp. 644-651, 2009.

[26] S. Raychaudhuri, K. V. Santosh, and H. V. Satish Babu, "Primary cutaneous adenoid cystic carcinoma of the chest wall: a rare entity," Journal of Cancer Research and Therapeutics, vol. 8, no. 4, pp. 633-635, 2012.

[27] R. R. Seethala, "An update on grading of salivary gland carcinomas," Head and Neck Pathology, vol. 3, no. 1, pp. 69-77, 2009.

[28] E. Naylor, P. Sarkar, C. S. Perlis, D. Giri, D. R. Gnepp, and L. Robinson-Bostom, "Primary cutaneous adenoid cystic carcinoma," Journal of the American Academy of Dermatology, vol. 58, no. 4, pp. 636-641, 2008.

[29] G. T. Desman, U. Ozerdem, and S. J. Shin, "Neighboring look-alikes: distinguishing between breast and dermatologic lesions," Advances in Anatomic Pathology, vol. 21, no. 4, pp. 228-247, 2014.

[30] D. P. Arps, M. P. Chan, R. M. Patel, and A. A. Andea, "Primary cutaneous cribriform carcinoma: report of six cases with clinicopathologic data and immunohistochemical profile," Journal of Cutaneous Pathology, vol. 42, no. 6, pp. 379-387, 2015.

[31] Y. G. Xu, M. Hinshaw, B. J. Longley, H. Ilyas, and S. N. Snow, "Cutaneous adenoid cystic carcinoma with perineural invasion treated by mohs micrographic surgery-a case report with literature review," Journal of Oncology, vol. 2010, Article ID 469049, 5 pages, 2010.

[32] T. Terada, "Expression of NCAM (CD56), chromogranin A, synaptophysin, c-KIT (CD117) and PDGFRA in normal nonneoplastic skin and basal cell carcinoma: an immunohistochemical study of 66 consecutive cases," Medical Oncology, vol. 30, no. 1, article 444, 2013.

[33] F. Petersson, H. Kutzner, D. V. Spagnolo et al., "Adenoid cystic carcinoma-like pattern in spiradenoma and spiradenocylindroma: a rare feature in sporadic neoplasms and those associated with Brooke-Spiegler syndrome," The American Journal of Dermatopathology, vol. 31, no. 7, pp. 642-648, 2009. 


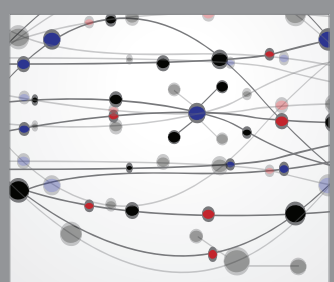

The Scientific World Journal
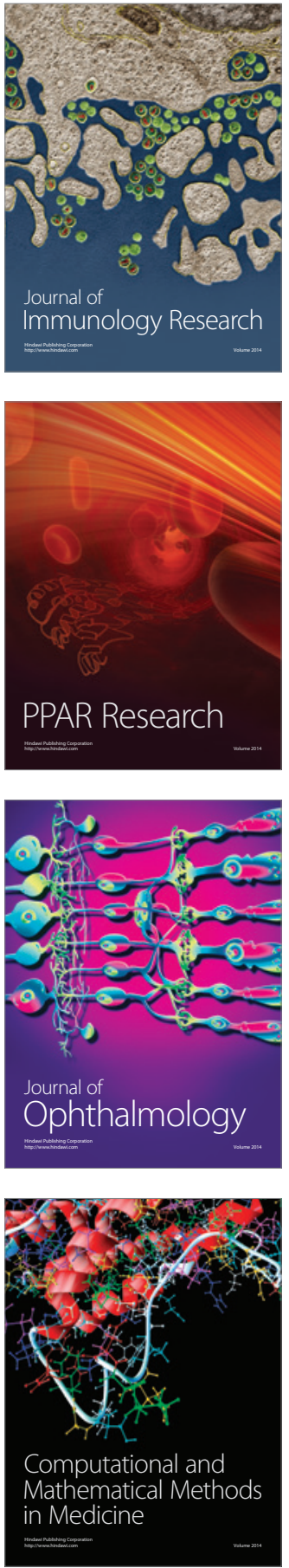

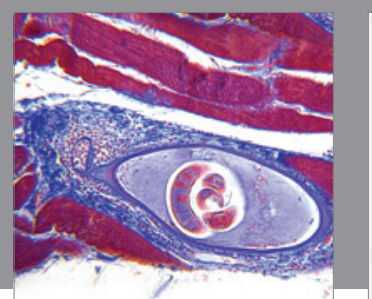

Gastroenterology Research and Practice
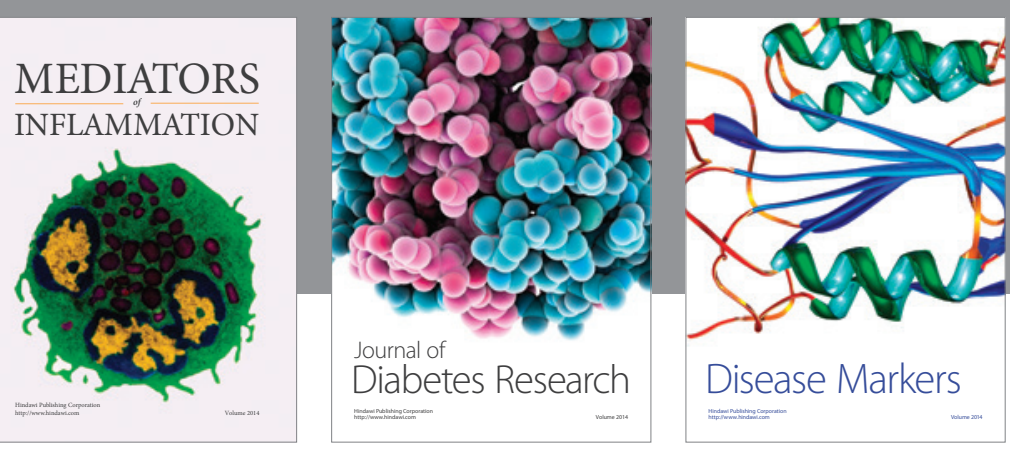

Disease Markers

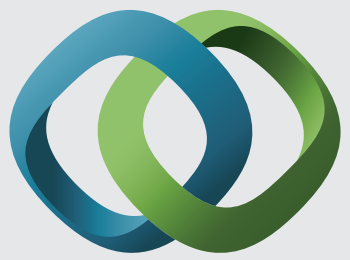

\section{Hindawi}

Submit your manuscripts at

https://www.hindawi.com
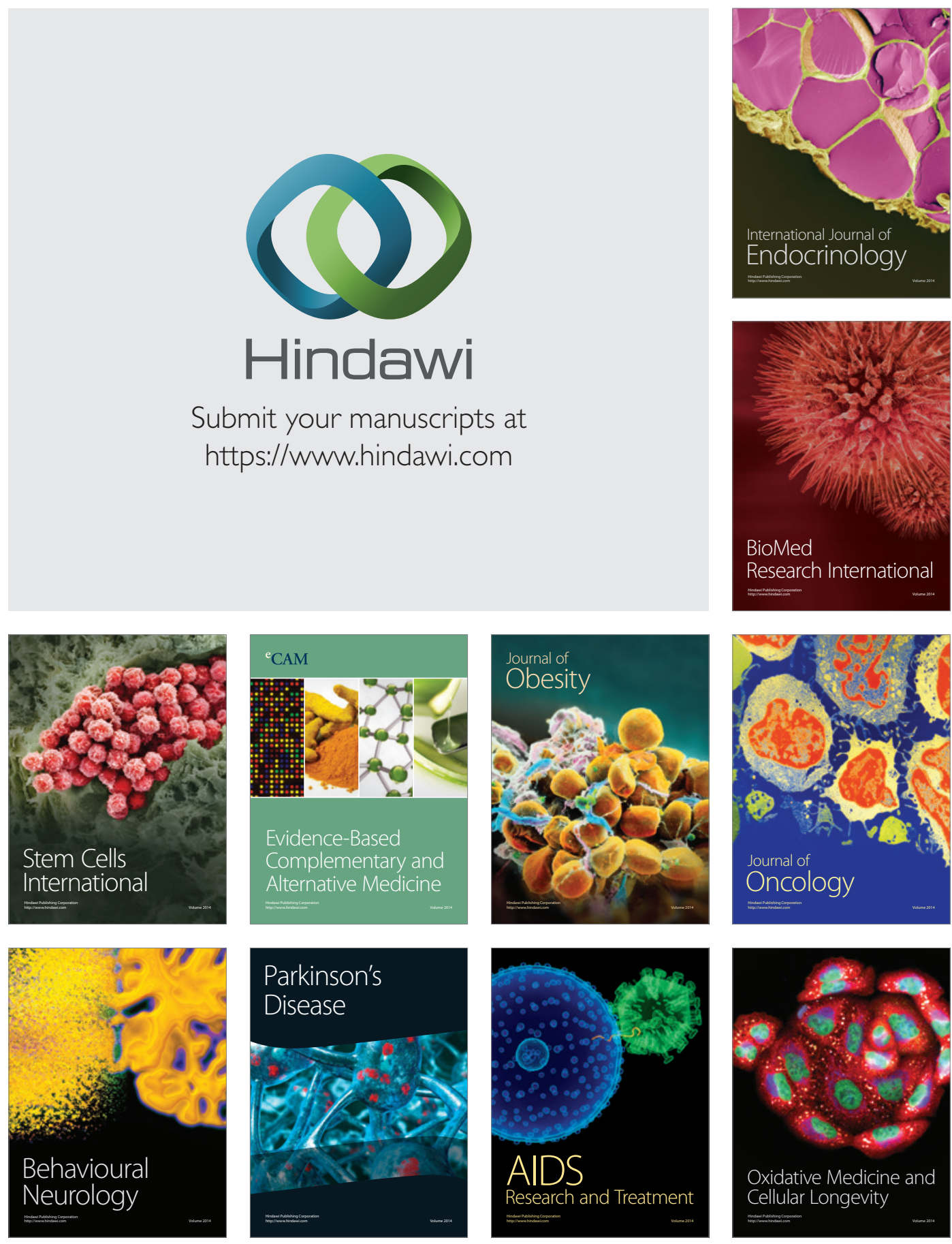